\title{
CORRIGENDUM
}

\section{Marker-free phase nanoscopy}

Yann Cotte, Fatih Toy, Pascal Jourdain, Nicolas Pavillon, Daniel Boss, Pierre Magistretti, Pierre Marquet \& Christian Depeursinge

Nature Photon. 7, 113-117 (2013); published online 20 January 2013; corrected online 16 April 2013.

In the version of this Letter originally published online, no competing financial interests were declared. However, the authors wish to acknowledge a relevant patent. The competing financial interests statement has been modified as shown below in the HTML and PDF versions of the Letter:

Yann Cotte, Nicolas Pavillon and Christian Depeursinge are named inventors on international patent WO/2011/121523 (publication date 06.10.2011, international filing date 28.03.2011), which is related to the techniques described in this Letter. 